\title{
First observation of an undular mesospheric bore in a Doppler duct
}

\author{
J. Fechine ${ }^{1}$, C. M. Wrasse ${ }^{2}$, H. Takahashi ${ }^{3}$, A. F. Medeiros ${ }^{1}$, P. P. Batista ${ }^{3}$, B. R. Clemesha ${ }^{3}$, L. M. Lima ${ }^{4}$, D. Fritts ${ }^{5}$, \\ B. Laughman ${ }^{5}$, M. J. Taylor ${ }^{6}$, P. D. Pautet ${ }^{3}$, M. G. Mlynczak ${ }^{7}$, and J. M. Russell ${ }^{8}$ \\ ${ }^{1}$ Universidade Federal de Campina Grande, Campina Grande, PB, Brazil \\ ${ }^{2}$ Universidade do Vale do Paraíba, UNIVAP/IP\&D, São José dos Campos, SP, Brazil \\ ${ }^{3}$ Instituto Nacional de Pesquisas Espaciais, São José dos Campos, Brazil \\ ${ }^{4}$ Universidade Estadual da Paraíba, Campina Grande, PB, Brazil \\ ${ }^{5}$ NorthWest Research Associates, Colorado Research Associates Division, Boulder, CO, USA \\ ${ }^{6}$ Utah State University, Logan, UT, USA \\ ${ }^{7}$ Atmospheric Sciences Division, NASA Langley Research Center, Hampton, VA, USA \\ ${ }^{8}$ Center for Atmospheric Sciences, Hampton University, Hampton, VA, USA
}

Received: 12 March 2008 - Revised: 10 February 2009 - Accepted: 10 February 2009 - Published: 1 April 2009

\begin{abstract}
On 1 October 2005, during the SpreadFEx campaign, a distinct mesospheric bore was observed over São João do Cariri $\left(7.4^{\circ} \mathrm{S}, 36.5^{\circ} \mathrm{W}\right)$, Brazil by using airglow allsky imagers. The event appeared both in the OI5577 and $\mathrm{OH}$ emissions, forming a well extended wave front which was followed by short waves from behind. Simultaneous wind and temperature data obtained by the meteor radar and the TIMED/SABER satellite instrument revealed that the bore event occurred during the Doppler ducting condition in the emission layers.
\end{abstract}

Keywords. Atmospheric composition and structure (Airglow and aurora) - Meteorology and atmospheric dynamics (Middle atmosphere dynamics; Waves and tides)

\section{Introduction}

A Mesospheric bore is one of the most interesting atmospheric wave phenomena that occur in the upper mesosphere and lower thermosphere region (MLT). It is a sharp wave front with a large horizontal extension (more than $500 \mathrm{~km}$ ) followed by a train of wave crests. It was first observed by Taylor et al. (1995) during the ALOHA-93 campaign using an all-sky imager. Dewan and Picard $(1998,2001)$ have explained the phenomenon as an internal undular bore propagating in the mesosphere. The occurrence of this sort of event would be associated with a temperature inversion layer that acts as a wave duct. Smith et al. (2003) and She et al. (2004) first reported simultaneous occurrence of the mesospheric bore and temperature inversion layer. Since then it has been recognized that the inversion layer could play an important role in the formation of the mesospheric bore.

In the equatorial region, a profusion of mesospheric bores has been reported by Fechine et al. (2005) and Medeiros et al. (2005). In these papers, the authors reported observations of more than 60 mesospheric bores over northeastern Brazil during a period of two years. This amount of data made it possible to study the preferential propagation direction of the wave fronts that in most of the cases the fronts propagate from the continent to the Atlantic Ocean. The data also showed that there were occurrences of complementarities which has not been predicted by Dewan and Picard (1998).

Simultaneous measurements of the mesospheric airglow by an all-sky imager and meteor radar wind profiles at São João do Cariri $\left(7.4^{\circ} \mathrm{S}, 36.5^{\circ} \mathrm{W}\right)$, and temperature profiles by TIMED/SABER satellite (Russell et al., 1999; Mertens et al., 2004) made it possible to carry out a more quantitative investigation of the mesospheric bore propagation conditions. The present work reports a case study of a mesospheric bore observed at São João do Cariri, Brazil. In Sect. 2, we present observational evidence of the mesospheric bore and the mesospheric environment when the bore passed. In Sect. 3, we discuss in the background wind field during the bore event, and in Sect. 4, we summarize the observation results. 
(a) TIMED/SABER Limb Soundings - 01/10/2005 - 2/10/2005

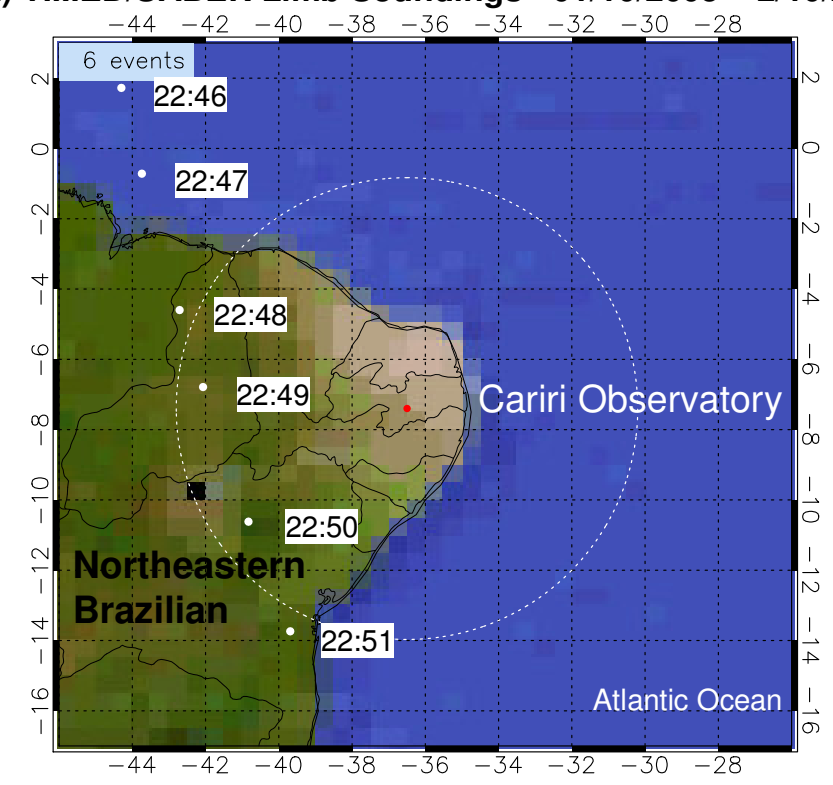

(b) All Sky Images - Cariri - 01/10/2005

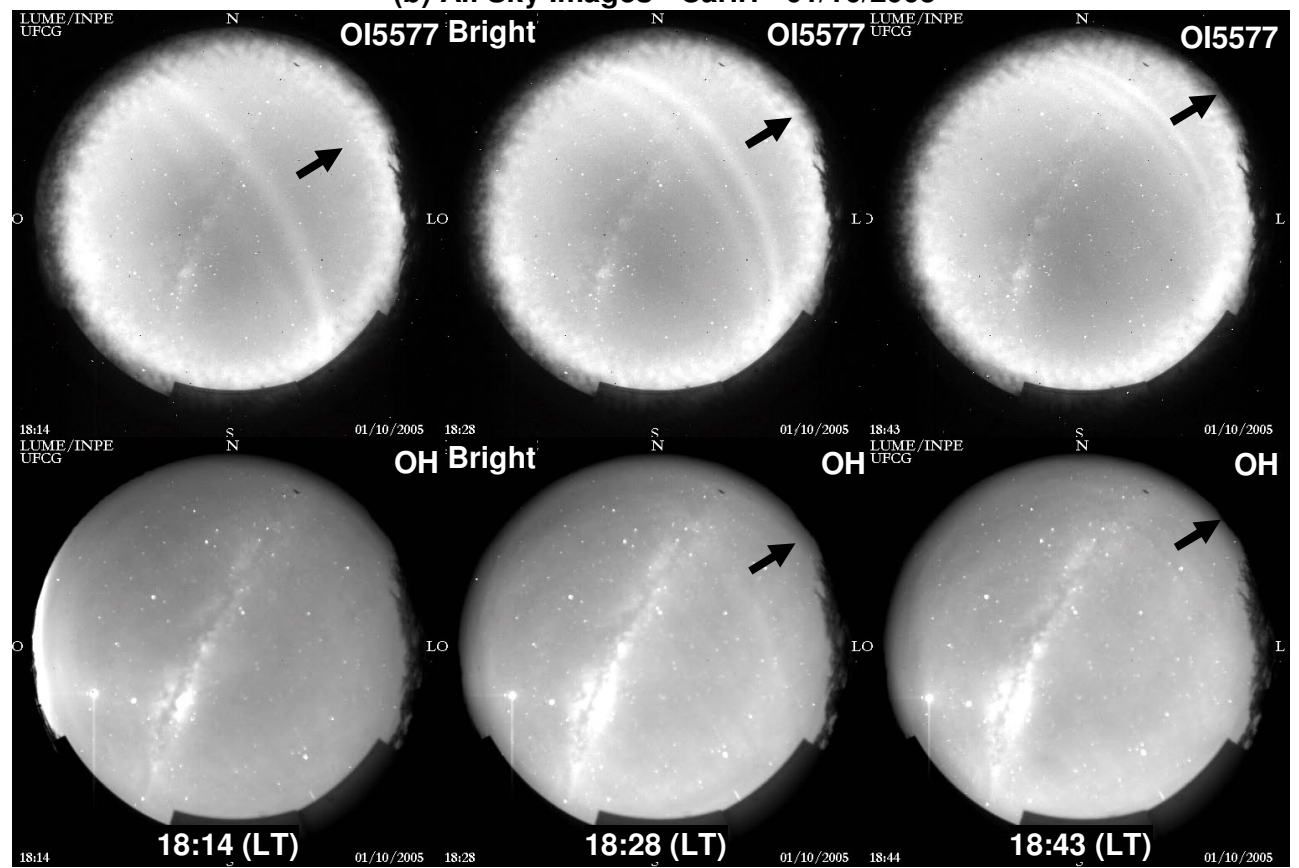

Fig. 1. (a) (top) TIMED/SABER soundings (tangent points represented by white dots) over the northeastern of Brazil between 22:00 and 24:00 (LT). The red dot marks the location of São João do Cariri and the dotted circle represents the area recorded by imager at airglow altitude. (b) Successive images of the all-sky OI5577 (top) and OH (bottom) airglow emission images showing the mesospheric front, observed on the night of 1 October 2005, during the SpreadFEx campaign. The arrows indicate the propagation direction of the wave front.

\section{Observation and results}

\subsection{Mesospheric front on 1 October 2005}

The First SpreadFEx Campaign was carried out from 22 September to November 2005, as a part of the NASA Living with a Star Program. The main objective of the campaign was the observation and modeling of gravity waves potentially capable of seeding plasma instabilities in the equatorial ionosphere (Fritts et al., 2009). During the campaign, several kinds of mesospheric front events were observed at São João do Cariri $\left(7.4^{\circ} \mathrm{S}, 36.5^{\circ} \mathrm{W}\right)$, Brazil, under different 

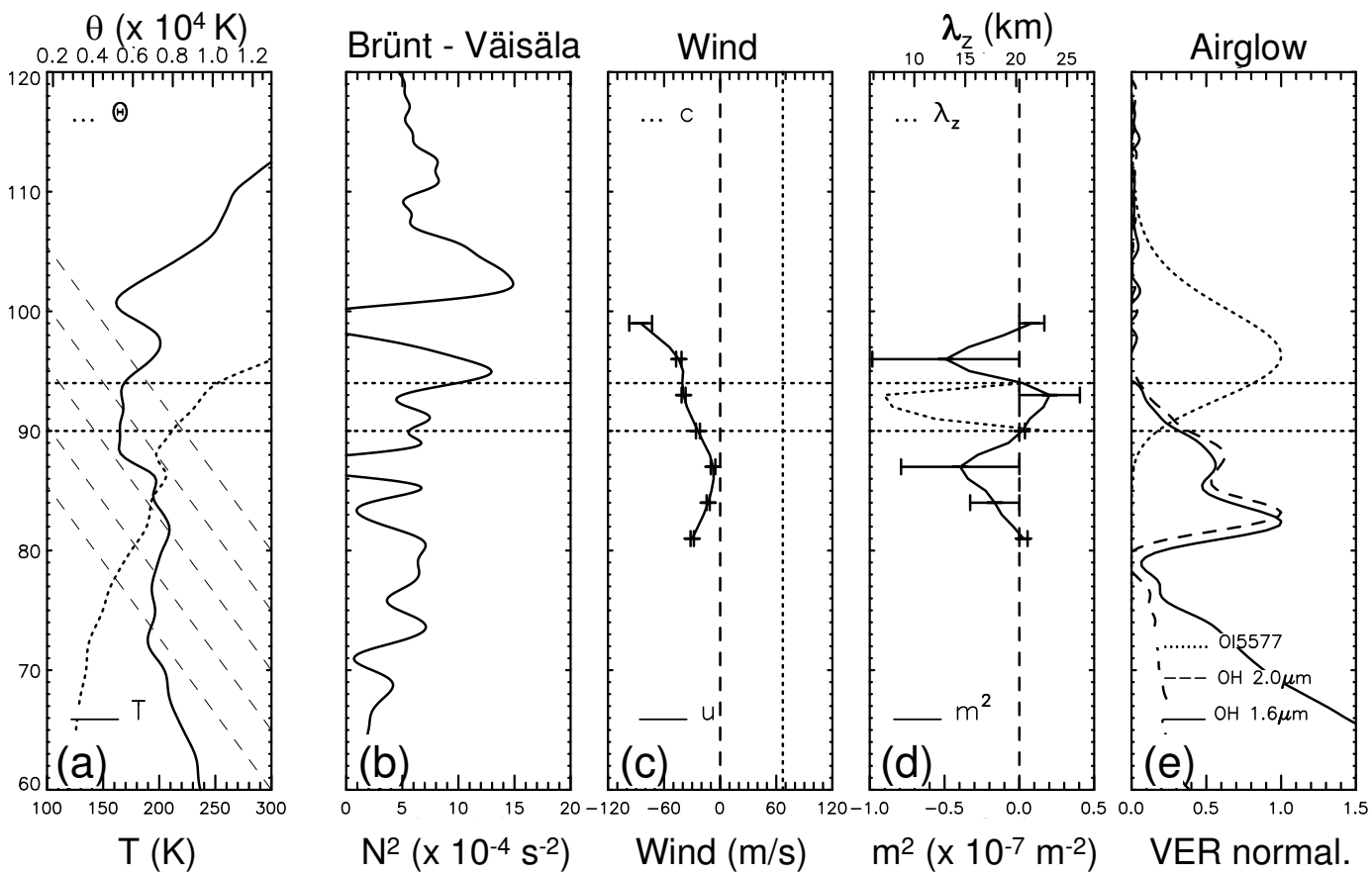

Fig. 2. (a) Kinetic temperature profile (solid line) obtained by the TIMED/SABER satellite on 1 October 2005, over São João do Cariri and potential temperature profile (dotted line). The dashed lines represent the adiabatic lapse rate. (b) Square of Brünt-Väisälä frequency profile. (c) Wind profile in the same propagation direction as the wave front measured at 18:00 (LT) by meteor radar (solid line). The dotted line represents the wave phase velocity. (d) Vertical squared wavenumber $\left(\mathrm{m}^{2}\right)$ (solid line) and vertical wavelength $\left(\lambda_{z}\right)$ (dotted line). (e) normalized volumetric emission rate (VER) profiles of the $\mathrm{OH}$ at $1.6 \mu \mathrm{m}$ (solid line) and $\mathrm{OH}$ at $2.0 \mu \mathrm{m}$ (dashed line) measured by the TIMED/SABER satellite, and OI5577 (dotted line) calculated using MSIS-90 atmospheric model. The horizontal solid lines in all graphs show the top and bottom of the duct.

propagation conditions. Figure 1a shows the location of the observatory (red dot) where the all-sky imager and meteor radar were operated. The all-sky imager observed the emissions of the $\mathrm{OH}$ Meinel band $(715-930 \mathrm{~nm})$ and OI green line at $557.7 \mathrm{~nm}$ (OI5577). Details of the imager system have been reported by Medeiros et al. (2001). The dotted circle (a diameter of $1200 \mathrm{~km}$ ) represents the area covered by the allsky imager at the $\mathrm{OH}$ emission altitude (around $87 \mathrm{~km}$ ). The white dots indicate the satellite TIMED/SABER temperature soundings (tangent points) between 22:00 and 24:00 (LT) on the night of 1 October 2005.

The first mesospheric front occurred on the night of 1 October 2005 over São João do Cariri. Figure 1b shows a sequence of three images observed from the OI5577 and $\mathrm{OH}$ emissions at 18:14, 18:28 and 18:43 LT. The image at 18:14 (LT) marks the beginning of observation in this evening. The OI5577 image shows a clear, sharp and extended form of a wave front, followed by three bright crests behind. The front moved towards NE with a velocity of $67 \mathrm{~m} / \mathrm{s}$. The $\mathrm{OH}$ images also presents a similar front structure although the structure being less clear and tenuous. It should be noted from the images that the $\mathrm{OH}$ front is located almost at a same line to the OI5577 front, indicating that both the wave front are in phase. The front lasted about $86 \mathrm{~min}$ and then disappeared in the NE horizon at 19:40(LT).
From the wave structures of the OI5577 image, we calculated the wave parameters using the FFT two-dimensional spectral analysis (Garcia and Taylor, 1997; Medeiros et al., 2003; Wrasse et al., 2007). The results showed that the mesospheric front with the horizontal wavelength of $42.4 \mathrm{~km}$ propagating towards NE ( $66^{\circ}$ of azimuth), observed period and phase speed of $7 \mathrm{~min}$ and $67.5 \mathrm{~ms}^{-1}$, respectively. Meteor radar wind data were used to calculate the intrinsic parameters of the wave.

\subsection{Mesospheric environment on the night of the event}

In order to investigate mesospheric environment during the bore event, wind profiles obtained by meteor radar, $\mathrm{OH}$ volumetric emission rate (VER) and temperature profiles obtained by the TIMED/SABER instrument (Mertens et al., 2004; Russell et al., 1999) were used. Figure 2a presents a temperature profile (solid line) obtained by the TIMED/SABER instrument at a mean tangent point coordinate $\left(4.6^{\circ} \mathrm{S} ; 42.7^{\circ} \mathrm{W}\right)$ at $22: 48(\mathrm{LT})$ on 1 October 2005. Potential temperature profile shown by the dotted line was derived from the temperature and pressure data obtained by TIMED/SABER. The increasing of the potential temperature between 70 and $95 \mathrm{~km}$ indicates a stable condition of the mesosphere. The dashed line represents the adiabatic lapse 
rate, i.e., $-9.8 \mathrm{~K} / \mathrm{km}$. Figure $2 \mathrm{~b}$ presents the square of BrüntVäisälä frequency. Analyzing Fig. 2a and b we can see that, in general, the mesosphere was stable, presenting only narrow regions around 71,87 and $99 \mathrm{~km}$ where $N^{2}$ was zero. Between 89 and $97 \mathrm{~km}$ we observe a stable region where $N^{2}$ has values between $6 \times 10^{-4} \mathrm{~s}^{-2}$ and $12 \times 10^{-4} \mathrm{~s}^{-2}$, i.e., a Brünt-Väisälä frequency from 4 to $8 \mathrm{~min}$, which agrees with the intrinsic period measured for the wave train behind the mesospheric front.

We also observe in the temperature profile an inversion layer between 93 and $97 \mathrm{~km}$, with the amplitude of $34 \mathrm{~K}$. Above the peak of the inversion layer the temperature decreases with a higher rate than the adiabatic. The thickness and amplitude of the mesospheric inversion layer (MIL) agree with the characteristics observed by Fechine et al. (2007) for MILs over São João do Cariri.

Comparing this observation with previous studies, the minimum temperature of the MIL was $166 \mathrm{~K}$, i.e., approximately $19 \mathrm{~K}$ below the mean minimum temperature. The peak temperature in the MIL was $201 \mathrm{~K}$, i.e., close to the mean maximum temperature of $205 \pm 5 \mathrm{~K}$. The bottom and top altitudes of the MIL (93 and $97 \mathrm{~km}$, respectively) are larger than the averages of MILs observed over São João do Cariri, which were $75 \pm 3 \mathrm{~km}$ and $83 \pm 4 \mathrm{~km}$, respectively.

Figure 2c shows the wind profile (solid line) in the wave front propagation direction, and the observed phase speed of the mesospheric bore (dotted line). The wind profile was obtained with the $3 \mathrm{~h}$ averaged and vertically interpolated for every one $\mathrm{km}$ in order to get one wind profile per hour. Analyzing Fig. 2c, we can see that the wind flows in the opposite direction of the bore.

Below $82 \mathrm{~km}$ the wind showed a velocity from -30 to $-40 \mathrm{~ms}^{-1}$, decreasing in magnitude until $87 \mathrm{~km}$, where the wind was around zero. Above this level the wind magnitude increased again reaching $-30 \mathrm{~ms}^{-1}$ at $91 \mathrm{~km}$ and $-60 \mathrm{~ms}^{-1}$ at $97 \mathrm{~km}$. Above $97 \mathrm{~km}$ the profile showed the largest negative values, between -60 and $-90 \mathrm{~ms}^{-1}$. Considering the wind velocity as $33.5 \mathrm{~ms}^{-1}$ in the height of the duct structure (90-94 km, Fig. 2d), we found the intrinsic phase velocity of $\sim 101 \mathrm{~ms}^{-1}$.

Figure $2 \mathrm{~d}$ shows vertical wavelength (dotted line) and squared wave number (solid line) profiles calculated for the mesospheric bore using the following gravity wave dispersion relation:

$m^{2}=\frac{N^{2}}{(\bar{u}-c)^{2}}-\frac{\bar{u}_{z z}}{(\bar{u}-c)}-k_{h}^{2}$,

where, $m$ is the vertical wave number, $N^{2}$ is the squared Brünt-Väisälä frequency; $\bar{u}$ is the basic wind velocity in the wave direction; $c$ is the observed phase, and $k_{h}=2 \pi / \lambda_{h}$ is the horizontal wave number.

The dispersion relation given in Eq. (1) is valid for gravity waves propagating in an environment where the effects of wind shear and temperature gradients can not neglect (Chimonas and Hines, 1986; Isler et al., 1997).
It is clear to see in the $\mathrm{m}^{2}$ profile the occurrence of two distinct regions around $96 \mathrm{~km}$ and $87 \mathrm{~km}$, where $m^{2}$ is negative. These regions are defined as the evanescent region, i.e, the regions where gravity waves cannot propagate vertically. Between these two evanescent regions exists another region where $m^{2}$ is positive, that allows the vertical propagation of gravity waves. This region configures a duct where gravity waves can propagate with minimum energy dissipation, surrounded by evanescent regions which inhibit vertical propagation (Chimonas and Hines, 1986; Fritts and Yuan, 1989). This duct is located between 90 and $94 \mathrm{~km}$ and is delimited by horizontal parallel lines (dotted lines) in all plots of Fig. 2.

Figure 2e presents the volumetric emission rate profiles of $\mathrm{OH}$ at $1.6 \mu \mathrm{m}$ (solid line) and $\mathrm{OH}$ at $2.0 \mu \mathrm{m}$ (dashed line) obtained by the TIMED/SABER instrument, together with OI5577 (dotted line) emissions calculated using the MSIS-90 model (Hedin, 1991), since we do not have direct measurement of the green line emission. We can observe in Fig. 2e that the emission peak of $\mathrm{OH}$ is localized at $82 \mathrm{~km}$, below the nominal altitude $(86 \mathrm{~km})$, while the peak of the OI5577 is localized at $96 \mathrm{~km}$. Also we observe that the duct region (horizontal dotted lines), defined by positive $\mathrm{m}^{2}$, contains a significant portion of the OI5577 layer, while only part of topside $\mathrm{OH}$ layer was within the duct. It is calculated that $\sim 20 \%$ of the OI5577 emission originated within the duct region, as compared to $\sim 8 \%$ of $\mathrm{OH}$ in $1.6 \mu \mathrm{m}$ and $\sim 11 \%$ of $\mathrm{OH}$ in $2.0 \mu \mathrm{m}$. This can explain the clear visible wave fronts observed in OI5577 emission as compared to the $\mathrm{OH}$. It is interesting to note that the duct was centered between 90 and $94 \mathrm{~km}$, above the $\mathrm{OH}$ and below the OI5577 emission peaks (82-83 and $96 \mathrm{~km}$, respectively). As the wave front shows a bright appearance in both the layers, this means that the observation doesn't agree with the complementary effect proposed by the Dewan and Picard (1998) model and described by Medeiros et al. (2005), which predict a decrease in emission intensity of airglow layer, when the duct is localized below the peak, in case of green line emission.

The physical parameters within the duct were calculated and summarized in Table 1. The application of these parameters as boundary conditions in future simulations of wave fronts, may contribute to improving our understanding of the environment and morphologies of mesospheric bores.

\section{Discussion}

The observed mesospheric front showed a horizontally extended wave front, which is in phase both at the OI5577 and $\mathrm{OH}$ emission layers. During the passage of the front over São João do Cariri, there was a ducting condition in the emission layers as mentioned in the previous section. These observational facts lead us to believe that the front should be a mesospheric bore suggested by Dewan and Picard (2001), which is: the presence of an extended bright front, followed by short wavelength wave trains and the presence of wave ducting 
Table 1. Physical parameters observed within the duct of mesospheric front on 1 October 2005.

\begin{tabular}{lcccccc}
\hline & $\begin{array}{c}T \\
(\mathrm{~K})\end{array}$ & $\begin{array}{c}\theta \\
(\mathrm{K})\end{array}$ & $\begin{array}{c}N^{2} \\
\left(\times 10^{-4} \mathrm{~s}^{-2}\right)\end{array}$ & $\begin{array}{c}u \\
\left(\mathrm{~ms}^{-1}\right)\end{array}$ & $\begin{array}{c}m^{2} \\
\left(\times 10^{-8} \mathrm{~m}^{-2}\right)\end{array}$ & $\begin{array}{c}\lambda_{z} \\
(\mathrm{~km})\end{array}$ \\
\hline Minimum & 164.9 & 7.975 & 4.5 & -40.5 & 0.2 & 7 \\
Maximum & 168.8 & 10.244 & 9.9 & -23.8 & 2.0 & 23 \\
Mean & 166.7 & 9.054 & 6.4 & -33.8 & 0.9 & 14.2 \\
\hline
\end{tabular}

condition. Several previous works have used the same criteria (Medeiros et al., 2001, 2005; Smith et al., 2003, 2005; She et al., 2004; Fechine et al., 2005).

A similar mesospheric wave front has also been observed by Swenson et al. (1998). They observed a bright $\mathrm{OH}$ airglow layer as a type of wall and a simultaneous increase of the local temperature. The sodium density also increased during the wall event. They interpreted the event as a passage of a large scale gravity wave, horizontal wavelength of $300-350 \mathrm{~km}$, period of $80 \mathrm{~min}$, phase speed of $75 \mathrm{~m} / \mathrm{s}$ and the vertical wavelength of $20 \mathrm{~km}$. They classified it as a traveling gravity wave but not as a bore because of that the observed parameters showed a vertical phase propagation form. Li et al. (2007) observed a similar phenomenon, a large intensity increase in the airglow and subsequent short period wave structure. They observed the intensity increase for both the $\mathrm{OH}$ and $\mathrm{O}_{2}$ atmospheric band emissions with a time lag of about 30-60 min. They concluded that the observed front was due to a large scale gravity wave. Our present results differ to their results. There is no trace of vertical phase propagation in the $\mathrm{OH}$ and OI5577 images. It indicates that the wave is trapped in a short height range propagating only in the horizontal direction.

\subsection{Propagation condition for the mesospheric front}

Recent papers that reported the occurrence of mesospheric bores with inversion layers (Smith et al., 2003, 2005) have proposed that the thermal duct would support the wave fronts. In the present case, however, it seems that the wind (the second term of Eq. 1) also has an important role in forming the ducting condition. Figure 3 shows an analysis of the $\mathrm{m}^{2}$ terms calculated using wind and temperature data for the mesospheric bore observed on 1 October 2005 over São João do Cariri.

Analyzing the contribution to $m^{2}$ (Fig. 3e) of each term in the dispersion relation (Eq. 1), we observe the following situation: the second derivative of the wind, $\left(\bar{u}_{z z} /(\bar{u}-c)\right)$ in Fig. 3c dominates the $m^{2}$ results, whereas the contribution of the temperature, $\left(-N^{2} /(\bar{u}-c)^{2}\right)$ in Fig. $3 \mathrm{~b}$, and horizontal wave number, $\left(-k_{h}^{2}\right)$ in Fig. $3 \mathrm{~d}$, terms are negligible. This means that the wind played a fundamental role in the duct formation where the mesospheric front propagates. For this reason it is necessary to include contributions of the wind profile to the dispersion relation whenever such events are analyzed.

Figure 4 shows intensification of the zonal and meridional winds at 14:00 and 17:00(LT). The wind patterns presented indicate a semi-diurnal tide oscillation. This type of intensification of the semi-diurnal tidal mode in the wind field has been reported by Lima et al. (2007) and Buriti et al. (2008). The zonal wind intensification was larger above $90 \mathrm{~km}$, reaching values of $-120 \mathrm{~ms}^{-1}$ (westward) at $97 \mathrm{~km}$. For the meridional wind the intensification was larger above $83 \mathrm{~km}$, The wind was increased from zero at $83 \mathrm{~km}$ to $70 \mathrm{~ms}^{-1}$ at $93 \mathrm{~km}$ where the meridional wind was maximum. When the wave front was observed (an interval between the vertical solid lines in the figure) we can see that the wind in the direction of the wave front propagation is between -10 and $-20 \mathrm{~ms}^{-1}$ below $84 \mathrm{~km}$, decreasing to approximately zero between 84 and $88 \mathrm{~km}$. The wind shows a strong gradient with velocities of $-20 \mathrm{~ms}^{-1}$ at $89 \mathrm{~km},-40 \mathrm{~ms}^{-1}$ at $92 \mathrm{~km}$, and $-60 \mathrm{~ms}^{-1}$ at $98 \mathrm{~km}$. Therefore, the wind profile in these regions is expected to play an important role in the propagation of the wave.

Figure 5 presents a contour map of the normalized $\mathrm{m}^{2}$ from 12:00 (LT) of 1 October 2005 to 12:00 (LT) of 2 October 2005 over São João do Cariri. In these contour plots, we assume that the time variation of $m^{2}$ is due only to the variation of the wind. Note from Eq. (1) that besides the wind, the temperature (included in the $N^{2}$ term) and the wave parameters, $c$ and $k_{h}^{2}$, can also vary with time. However, the temperature and horizontal wave number variations should not strongly influence $m^{2}$, since their contribution are small compared to the wind term, in the present case.

Figure 5 clearly shows a possible ducting region between 90 and $94 \mathrm{~km}$ (horizontal solid lines), also visible in Fig. 2d, at the time of the mesospheric bore occurrence (vertical solid lines). At the same time we can also observe two evanescent regions at $\sim 87$ and $\sim 96 \mathrm{~km}$. The lower evanescent region was first observed at 16:30(LT), persisting until 23:00(LT), and the upper region occurred between 17:00 and 01:00 (LT). The evanescent regions above and below strongly limit the vertical propagation of the waves, and consequently, resulting loss of energy (Nappo, 2002).

The present result is somewhat new observational evidence and an important fact since various reports in the literature have associated mesospheric bore occurrence only with the existence of temperature inversion layers (Smith et al., 


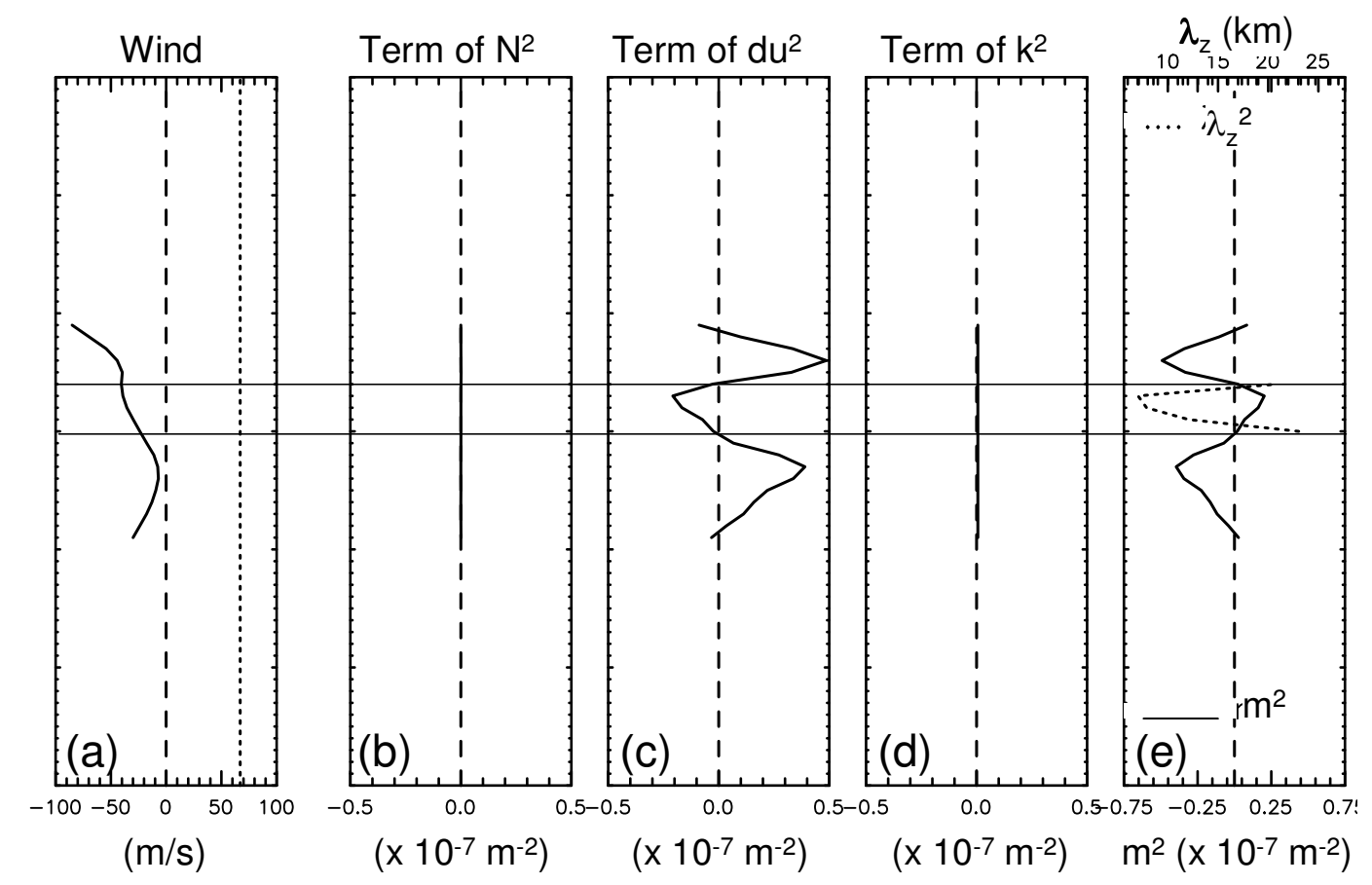

Fig. 3. Analysis of the $m^{2}$ terms calculated from wind and temperature data for mesospheric bore observed on 1 October 2005, over São João do Cariri.

2003, 2005; She et al., 2004). From a model of the mesospheric bore Dewan and Picard $(1998,2001)$ has already pointed out that the duct may be generated by some combination of wind shear and a temperature inversion layer. The present results support their model study.

The first evidence of that wind could play an important role in the development of mesospheric fronts appeared in Batista et al. (2002). In this paper, the authors investigated the wave front observed by Medeiros et al. (2001) over Cachoeira Paulista, SP, Brazil. Both papers showed that an intense wind shear occurred simultaneously with the event. Smith et al. (2003) also verified the occurrence of strong wind shear in the same height range of the wave front. These authors, however, limited their discussion in the temperature inversion layer for formation of the ducting condition. She et al. (2004) observed a mesospheric front propagating in the opposite direction to strong wind, which also suggests the importance of the wind in the configuration of a duct.

Shiokawa et al. (2006) observed an intense wind shear $\left(80 \mathrm{~m} \mathrm{~s}^{-1} \mathrm{~km}^{-1}\right)$ in the altitude of a mesospheric front over Kototabang, Indonesia. The authors speculated the possibility that the wind played an important role in the wave front generation. However, investigating the wave front propagation conditions, they used a dispersion relation of a gravity wave for an atmosphere without wind shear or curvature given by:

$m^{2}=\frac{N^{2}}{(\bar{u}-c)^{2}}-k_{h}^{2}-\frac{1}{4 H^{2}}$, where $H$ is the height scale. Based on the results of this dispersion relation, the authors concluded that the duct conditions proposed by Dewan and Picard (1998) were not consistent with the mesospheric front observed.

Thus, the case study of the wave front observed at São João do Cariri on 1 October 2005, appears to be the first demonstration that the wind played an important role in the propagation of the mesospheric bore. Moreover, it showed that the dispersion relation given by Eq. (1) must be used, because it is more realistic to consider both the wind profile and temperature gradients when diagnosing the conditions of ducting.

\section{Conclusions}

On 1 October 2005, during the SpreadFEx campaign, a mesospheric bore in the $\mathrm{OH}$ and OI5577 emission layers over São João do Cariri, PB, Brazil was observed. The main results found in this work are listed below:

- The analysis of the propagation conditions allows one to conclude that the observed mesospheric front was an undular mesospheric bore supported by a wind generated Doppler duct. This appears to be the first report of this phenomenon in the literature;

- A strong and large variability of the wind profile generated mainly by the semi-diurnal tide seems to be responsible for forming the Doppler duct condition. 

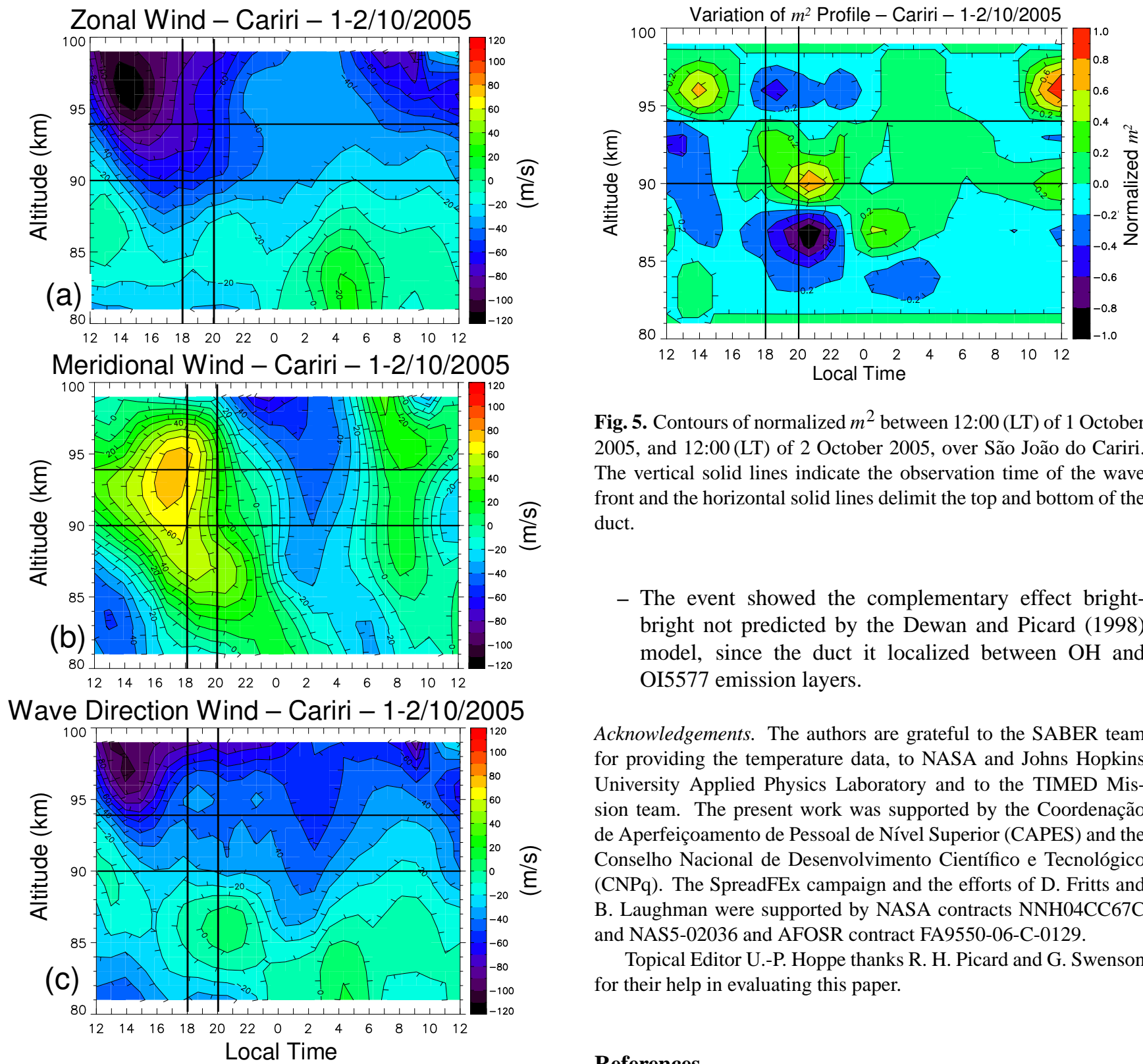

Fig. 5. Contours of normalized $\mathrm{m}^{2}$ between 12:00 (LT) of 1 October 2005, and 12:00 (LT) of 2 October 2005, over São João do Cariri. The vertical solid lines indicate the observation time of the wave front and the horizontal solid lines delimit the top and bottom of the duct.

- The event showed the complementary effect brightbright not predicted by the Dewan and Picard (1998) model, since the duct it localized between $\mathrm{OH}$ and OI5577 emission layers.

Acknowledgements. The authors are grateful to the SABER team for providing the temperature data, to NASA and Johns Hopkins University Applied Physics Laboratory and to the TIMED Mission team. The present work was supported by the Coordenação de Aperfeiçoamento de Pessoal de Nível Superior (CAPES) and the Conselho Nacional de Desenvolvimento Científico e Tecnológico (CNPq). The SpreadFEx campaign and the efforts of D. Fritts and B. Laughman were supported by NASA contracts NNH04CC67C and NAS5-02036 and AFOSR contract FA9550-06-C-0129.

Topical Editor U.-P. Hoppe thanks R. H. Picard and G. Swenson for their help in evaluating this paper.

\section{References}

Fig. 4. Contour plot of (a) zonal wind, (b) meridional wind and (c) wind in the direction of wave propagation measured with meteor radar between 12:00 (LT) of 1 October 2005, and 12:00 (LT) of 2 October 2005, over São João do Cariri, PB, Brazil. The vertical solid lines indicate the observation time of the wave front and the horizontal solid lines delimit the top and bottom of the duct showed in the Fig. 2.

- Different parts of the $\mathrm{OH}$ in $1.6 \mu \mathrm{m}(8 \%)$, in $2.0 \mu \mathrm{m}$ $(11 \%)$ and OI5577 (20\%) emission layers contained within the duct explain the more distinct appearance of the mesospheric bore in the OI5577 images than in the OH images;

Batista, P. P., Clemesha, B. R., Simonich, D. M., Taylor, M. J., Takahashi, H., GOBBI, D., Batista, I. S., Buriti, R. A., and Medeiros, A. F.: Simultaneous lidar observation of a sporadic sodium layer, a "wall" event in the $\mathrm{OH}$ and OI5577 airglow images and the meteor winds, J. Atmos. Solar-Terr. Phys., 64, 1327-1335, 2002.

Buriti, R. A., Hocking, W. K., Batista, P. P., Medeiros, A. F., and Clemesha, B. R.: Observations of equatorial mesospheric winds over Cariri $\left(7.4^{\circ} \mathrm{S}\right)$ by a meteor radar and comparison with existing models, Ann. Geophys., 26, 485-497, 2008, http://www.ann-geophys.net/26/485/2008/.

Chimonas, G. and Hines, C. O.: Doppler Ducting of Atmospheric Gravity-Waves, J. Geophys. Res., 91, 1219-1230, 1986.

Dewan, E. M. and Picard, R. H.: Mesospheric bores, J. Geophys. Res., 103, 6295-6306, 1998.

Dewan, E. M. and Picard, R. H.: On the origin of mesospheric bores, J. Geophys. Res., 106, 2921-2928, 2001. 
Fechine, J., Medeiros, A. F., Buriti, R. A., Takahashi, H., and Gobbi, D.: Mesospheric bore events in the equatorial middle atmosphere, J. Atmos. Solar-Terr. Phys., 67, 1774-1778, 2005.

Fechine, J., Wrasse, C. M., Takahashi, H., Mlynczak, M. G., and Russell, J. M.: Lower Mesospheric Inversion Layers over Brazilian Equatorial Region using TIMED/SABER Temperature Profiles, J. Adv. Space Res., 41, 1447-1453, doi:10.1016/j.asr.2007.04.070, 2007.

Fritts, D. C., Abdu, M. A., Batista, I. S., Batista, P. P., Buriti, R., Clemesha, B. R., Comberiate, J., Dautermann, T., de Paula, E., Fechine, J., Fejer, B., Gobbi, D., Haase, J., Kamalabadi, F., Laughman, B., Lima, L. M., Liu, H. L., Medeiros, A. F., Pautet, D., Riggin, D. M., São Sabbas, F., Sobral, J. H. A., Stamus, P., Takahashi, H., Taylor, M. J., Vadas, S. L., and Wrasse, C. M.: The Spread F Experiment (SpreadFEx): Program overview and first results, Earth Planet. Space Sci., in press, 2009.

Fritts, D. C. and Yuan, L.: An analysis of gravity wave ducting in the atmosphere: Eckarts resonances in thermal and Doppler ducts, J. Geophys. Res., 94, 18455-18466, 1989.

Garcia, F. J. and Taylor, M. J.: Two-dimensional spectra-analysis of mesospheric airglow data, Appl. Optics, 36(29), 7374-7385, 1997.

Hedin, A. E.: Extension of the MSIS Thermospheric Model into the Middle and Lower Atmosphere, J. Geophys. Res., 96, 11591172, 1991.

Isler, J. R., Taylor, M. J., and Fritts, D. C.: Observational Evidence of Wave Ducting and Evanescence in the Mesosphere, J. Geophys. Res., 102, 26301-26313, 1997.

Li, F., Swenson, G. R., Liu, A. Z., Taylor, M. J., and Zhao, Y.: Investigation of a "wall" wave event, J. Geophys. Res., 112, D04104, doi:10.1029/2006JD007213, 2007.

Lima, L. M., Paulino, A. R., Medeiros, A. F., Buriti, R. A., Batista, P. P., Clemesha, B. R., and Takahashi, H.: First observations of the diurnal and semidiurnal oscillations in the mesospheric winds over São João do Cariri-PB, Brazil, Revista Brasileira de Geofísica, 25, 35-41, 2007.

Medeiros, A. F., Taylor, M. J., Takahashi, H., Batista, P. P., and Gobbi, D.: A unusual airglow wave event observed at Cachoeira Paulista $23^{\circ}$ S, Adv. Space Res., 27, 1749-1754, 2001.

Medeiros, A. F., Taylor, M. J., Takahashi, H., Batista, P. P., and Gobbi, D.: An Investigation of gravity wave activity in the low-latitude upper mesosphere: propagation direction and wind filtering, J. Geophys. Res., 108(D14), 4411, doi:10.1029/2002JD002593, 2003.

Medeiros, A. F., Fechine, J., Buriti, R. A., Takahashi, H., Wrasse, C. M., and Gobbi, D.: Response of $\mathrm{OH}, \mathrm{O} 2$, and OI5577 airglow emissions to the mesospheric bore in the equatorial region of Brazil, Adv. Space Res., 35, 1971-1975, 2005.
Mertens C. J., Schmidlin, F. J., Goldberg, R. A., Remsberg, E. E., Pesnell, W. D., Russell III, J. M., Mlynczak, M. G., LópezPuertas, M., Wintersteiner, P. P., Picard, R. H., Winick, J. R., and Gordley, L. L.: SABER observations of mesospheric temperatures and comparisons with falling sphere measurements taken during the 2002 Summer MaCWAVE campaign, Geophys. Res. Lett., 31, 3105-3110, 2004.

Nappo, C. J.: An Introduction to atmospheric gravity waves, London, Academic Press, 276 p., 2002.

Russell III, J. M., Mlynczak, M. G., Gordley, L. L., Tansock, J., and Esplin, R.: An overview of the SABER experiment and preliminary calibration results, Proceedings of the SPIE, 44th Annual Meeting, Denver, Colorado, 18-23 July, 3756, 277-288, 1999.

She, C. Y., Li, T., Williams, B. P., Yuan, T., and Picard, R. H.: Concurrent $\mathrm{OH}$ imager and sodium temperature/wind lidar observation of a mesopause region undular bore event over Fort Collins/Platteville, Colorado, J. Geophys. Res., 109, 2210722115, 2004.

Shiokawa, K., Suzuki, S., Otsuka, Y., Ogawa, T., Nakamura, T., Mlynczak, M. G., and Russell III, M. J.: A Multi-Instrument Measurement of a Meso spheric Front-Like Structure at the Equator, J. Meteor. Soc. Japan, 84, 305-316, 2006.

Smith, S. M., Taylor, M. J., Swenson, G. R., She, C. Y., Hocking, W., Baumgardner, J., and Mendillo, M.: A multidiagnostic investigation of the meso spheric bore phenomenon, J. Geophys. Res., 108, 1083-1101, 2003.

Smith, S., Friedman, M. J., Raizada, S., Tepley, C., Baumgardner, J., and Mendillo, M.: Evidence of mesospheric bore formation from a breaking gravity wave event: simultaneous imaging and lidar measurements, J. Atmos. Solar-Terr. Phys., 67, 345-356, 2005.

Swenson, G. R., Qian, J., Plane, J. M. C., Espy, P. J., Taylor, M. J., Turnbull, D. N., and Lowe, R. P.: Dynamical and chemical aspects of the mesospheric Na "wall" event on October 9, 1993 during the ALOHA campaign, J. Geophys. Res., 103, 6361-6380, 1998.

Taylor, M. J., Turnbull, D. N., and Lowe, R. P.: Spectrometric and imaging measurements of a spectacular gravity wave event observed during the ALOHA-93 campaign, Geophys. Res. Lett., 20, 2849-2852, 1995.

Wrasse, C. M., Takahashi, H., Medeiros, A. F., Lima, L. M., Taylor, M. J., Gobbi, D., and Fechine, J.: Determinação dos Parâmetros de Ondas de Gravidade Através da Análise Espectral de Imagens de Aeroluminescência, Brazilian J. Geophys., 25, 257-266, 2007. 